\title{
Synthesis of Porous NiO Nanocrystals with Controllable Surface Area and Their Application as Supercapacitor Electrodes
}

\author{
Xiaojun Zhang ${ }^{1,2}$, Wenhui Shi ${ }^{1}$, Jixin Zhu ${ }^{1}$, Weiyun Zhao ${ }^{1}$, Jan Ma ${ }^{1}$, Subodh Mhaisalkar ${ }^{1,3}$, Tuti Lim Maria ${ }^{4,5}$, \\ Yanhui Yang ${ }^{6}$, Hua Zhang ${ }^{1}$, Huey Hoon $\mathrm{Hng}^{1}(\bowtie)$, and Qingyu Yan ${ }^{1,3}(\varangle)$ \\ ${ }^{1}$ School of Materials Science and Engineering, Nanyang Technological University, 639798, Singapore \\ ${ }^{2}$ College of Chemistry and Materials Science, Anhui Normal University, Wuhu 241000, China \\ ${ }^{3}$ Energy Research Institute, Nanyang Technological University, 637459, Singapore \\ ${ }^{4}$ School of Civil and Environmental Engineering, Nanyang Technological University, 639798, Singapore \\ ${ }^{5}$ School of Life Sciences and Chemical Technology, Ngee Ann Polytechnic, 535 Clementi Road, Singapore \\ ${ }^{6}$ School of Chemical and Biomolecular Engineering, Nanyang Technological University, 637459, Singapore \\ Received: 28 June 2010 / Revised: 29 July 2010 / Accepted: 30 July 2010 \\ (C) The Author(s) 2010. This article is published with open access at Springerlink.com
}

\begin{abstract}
We report a facile way to grow various porous $\mathrm{NiO}$ nanostructures including nanoslices, nanoplates, and nanocolumns, which show a structure-dependence in their specific charge capacitances. The formation of controllable porosity is due to the dehydration and re-crystallization of $\beta-\mathrm{Ni}(\mathrm{OH})_{2}$ nanoplates synthesized by a hydrothermal process. Thermogravimetric analysis shows that the decomposition temperature of the $\beta$-Ni( $(\mathrm{OH})_{2}$ nanostructures is related to their morphology. In electrochemical tests, the porous $\mathrm{NiO}$ nanostructures show stable cycling performance with retention of specific capacitance over 1000 cycles. Interestingly, the formation of nanocolumns by the stacking of $\beta$ - Ni(OH $)_{2}$ nanoslices/plates favors the creation of small pores in the $\mathrm{NiO}$ nanocrystals obtained after annealing, and the surface area is over five times larger than that of $\mathrm{NiO}$ nanoslices and nanoplates. Consequently, the specific capacitance of the porous $\mathrm{NiO}$ nanocolumns ( $390 \mathrm{~F} / \mathrm{g}$ ) is significantly higher than that of the nanoslices $(176 \mathrm{~F} / \mathrm{g})$ or nanoplates $(285 \mathrm{~F} / \mathrm{g})$ at a discharge current of $5 \mathrm{~A} / \mathrm{g}$. This approach provides a clear illustration of the process-structure-property relationship in nanocrystal synthesis and potentially offers strategies to enhance the performance of supercapacitor electrodes.
\end{abstract}

\section{KEYWORDS}

$\mathrm{Ni}(\mathrm{OH})_{2}, \mathrm{NiO}$, porous nanocrystals, supercapacitor

\section{Introduction}

Porous nanostructures have received great attention because of their wide-ranging applications, such as in lithium-ion batteries [1-3], ion exchange membranes [4], catalysis supports [5-8], solar cells [9], and super- capacitor electrodes [10-14] due to their high surface area and enhanced interaction with the environment [15]. In the case of charge storage applications, transition metal oxide nanostructures are attractive candidates by virtue of their excellent pseudocapacitive behavior and high electrical conductivity [16-21]. Furthermore,

Address correspondence to Huey Hoon Hng, ashhhng@ntu.edu.sg; Qingyu Yan, alexyan@ntu.edu.sg 
transforming bulk transition metal oxides into nanoporous structures has been proposed to have the advantage of effectively alleviating the strain generated during the ion insertion/desertion process and leading to improved cycling charge/discharge performance $[2,3]$. Among such oxides, $\mathrm{NiO}$ is of particular interest owing to its high theoretical specific capacitance of 2573 F/g [22, 23], high chemical/thermal stability, ready availability, environmentally benign nature and lower cost as compared to the state-of-the-art supercapacitor material $\mathrm{RuO}_{2}[24,25]$. There have been a variety of reports of the synthesis of different $\mathrm{NiO}$ nanostructures including porous nano/microspheres [26], nanoflowers [27], nanosheets [28], and nanofibers [29]. It has been shown that the electrochemical performance of $\mathrm{NiO}$ nanocrystals largely depends on its microstructure, surface area, and the presence of dopants [30-35], suggesting that the development of controlled syntheses of $\mathrm{NiO}$ nanostructures with the desired features, e.g., high electronic conductivity, low diffusion resistance to protons/cations, and high electroactive area is of paramount importance. Although several other techniques-such as surfactanttemplate [36], sol-gel [37-39], anodization [40], and hard template [41-43] methods-have been reported for synthesizing porous nanocrystals, solvothermal/ hydrothermal techniques $[3,30]$ are of particular interest as they are flexible and can be readily adapted to large scale production. Herein, we report a facile way to synthesize porous $\mathrm{NiO}$ nanoslices, nanoplates, and nanocolumns with adjustable surface area, and that these $\mathrm{NiO}$ nanostructures show a structure-dependent specific charge capacitance. The dehydration and re-crystallization of $\beta-\mathrm{Ni}(\mathrm{OH})_{2}$ nanoplates are shown to be vital steps in controlling the pore formation. Formation of nanocolumns by stacking $\beta-\mathrm{Ni}(\mathrm{OH})_{2}$ nanoslices/plates favors the formation of small pores in the resulting $\mathrm{NiO}$ nanocrystals, for which the surface area is significantly higher than that of $\mathrm{NiO}$ nanoslices and nanoplates. The porous $\mathrm{NiO}$ nanocolumns also show higher specific capacitance $(390 \mathrm{~F} / \mathrm{g})$ at a discharge current of $5 \mathrm{~A} / \mathrm{g}$ than that of nanoslices and nanoplates (285 and $176 \mathrm{~F} / \mathrm{g}$, respectively). Although there are reports in the literature of the synthesis of $\mathrm{NiO}$ nanocrystals with higher specific capacitances, e.g., porous $\mathrm{NiO}$ spheres [26] with specific capacitances
$>525 \mathrm{~F} / \mathrm{g}$ at a discharge current of $4 \mathrm{~A} / \mathrm{g}$ and $\mathrm{NiO}$ nanoflowers [27] with specific capacitances of $\sim 800 \mathrm{~F} / \mathrm{g}$ at a discharge current of $10 \mathrm{~mA}$, the current work demonstrates a clear process-related trend in the specific capacitance of the resulting electrode materials, which may provide an additional strategy to improve the performance of supercapacitors made of various materials.

\section{Experimental}

\subsection{Chemicals}

$\mathrm{NiCl}_{2} \cdot 6 \mathrm{H}_{2} \mathrm{O}$, ethanol, $\mathrm{NaOH}, \mathrm{NH}_{3} \cdot \mathrm{H}_{2} \mathrm{O}$, and $\mathrm{KOH}$ were purchased from Sigma Chemical Corp. All chemicals were used as received without any further purification. Millipore water was used in all experiments.

\subsection{Synthesis of various $\mathrm{Ni}(\mathrm{OH})_{2}$ nanoplates and nanocolumns}

In a typical synthesis, $0.02 \mathrm{mmol}$ of $\mathrm{NiCl}_{2} \cdot 6 \mathrm{H}_{2} \mathrm{O}$ was dissolved in $10 \mathrm{~mL}$ of deionized water under ambient conditions. The $\mathrm{pH}$ of the solution was then adjusted to 12,13 , or 14 by adding $\mathrm{NaOH}$ solution. The solutions were stirred vigorously for $1 \mathrm{~h}$ and transferred into an $80-\mathrm{mL}$ steel autoclave. The autoclave was sealed and maintained at $160{ }^{\circ} \mathrm{C}$ for $8 \mathrm{~h}$, and then allowed to cool to room temperature. The products were cleaned by repeated washing with ethanol/distilled water and centrifuging.

\subsection{Synthesis of porous $\mathrm{NiO}$ nanoslices, nanoplates and nanocolumns}

Porous nickel oxide samples were obtained by annealing the as-prepared $\mathrm{Ni}(\mathrm{OH})_{2}$ nanocrystals at $400{ }^{\circ} \mathrm{C}$ for about $2 \mathrm{~h}$.

\subsection{Characterization}

X-ray powder diffraction (XRD) patterns were recorded on a Shimadzu XRD-6000 X-ray diffractometer at a scan rate of $0.05 \%$ with the $2 \theta$ range from 10 to $80^{\circ}$, using $\mathrm{Cu} \mathrm{K} \alpha$ radiation. The size and morphology of the samples were characterized using a field-emission scanning electron microscope (SEM) (JEOL JSM6335) operating at $10 \mathrm{kV}$. High-resolution transmission 
electron microscopy (HRTEM) and selected-area electron diffraction (SAED) measurements were carried out using a JEOL 2010 system operating at $200 \mathrm{kV}$. Nitrogen adsorption/desorption isotherms were measured on a Micromeritics TriStar 3000 porosimeter (mesoporous characterization) and Micromeritics ASAP 2020 (microporous characterization) at $77 \mathrm{~K}$. All samples were outgassed at $100{ }^{\circ} \mathrm{C}$ for $6 \mathrm{~h}$ under vacuum before measurements were recorded. The specific surface areas were calculated using the Brunauer-Emmett-Teller (BET) method. Pore size distribution (PSD) plots were obtained by the BarrettJoyner-Halenda (BJH) method using the desorption branch and a cylindrical pore model. Micropore size distribution (MPSD) plots were obtained by the Horvath and Kawazoe (HK) method using a cylindrical pore model. Thermogravimetric analysis-differential scanning calorimetry (TG-DSC) measurements were conducted on a NETZSCH STA $449 \mathrm{C}$ apparatus in an air flow of $20 \mathrm{~mL} / \mathrm{min}$ with a heating rate of $10 \mathrm{~K} / \mathrm{min}$.

\subsection{Electrochemical tests}

The working electrode was prepared by mixing the electroactive material ( $\mathrm{NiO}, 85 \mathrm{wt} . \%)$, acetylene black (10 wt $\%)$, and poly(tetrafluoroethylene) (5 $\mathrm{wt} \%)$. The mixture was then pressed onto a nickel grid $\left(1 \times 1 \mathrm{~cm}^{2}\right)$ and dried at $100{ }^{\circ} \mathrm{C}$. The electrolyte used was aqueous
$\mathrm{KOH}$ solution $(1 \mathrm{~mol} / \mathrm{L})$. The electrochemical performance of the $\mathrm{NiO}$ samples was evaluated on a $\mathrm{CHI}$ 660B workstation for cyclic voltammetry $(\mathrm{CV})$ and chronopotentiometry $(\mathrm{CP})$ tests by using a threeelectrode cell with $\mathrm{Pt}$ foil as the counter electrode and a saturated calomel electrode (SCE) as the reference electrode.

\section{Results and discussion}

The synthesis involves two steps: (1) formation of different $\beta-\mathrm{Ni}(\mathrm{OH})_{2}$ nanocrystals; (2) conversion of the $\beta-\mathrm{Ni}(\mathrm{OH})_{2}$ to porous $\mathrm{NiO}$. The SEM images in Fig. 1 reveal the morphologies of the $\mathrm{Ni}(\mathrm{OH})_{2}$ nanostructures prepared under different synthesis conditions. In the crystal structure of $\mathrm{Ni}(\mathrm{OH})_{2}$, two $\mathrm{Ni}^{2+}$ ions in two adjacent (100) planes are linked through one $\mathrm{OH}^{-}$ ion, and two $\mathrm{Ni}^{2+}$ ions in two adjacent (001) planes are separated by two layers of $\mathrm{OH}^{-}$ions. Therefore, the $\mathrm{Ni}(\mathrm{OH})_{2}$ nanostructure can be tuned by adjusting the $\mathrm{pH}$ of the synthesis solution. At $\mathrm{pH} 14$, the products are mainly hexagonal nanoslices with a diameter of $\sim 300 \mathrm{~nm}$ and a thickness of 5-10 nm (see Figs. 1(a) and $1(\mathrm{~d})$ ). Decreasing the $\mathrm{pH}$ value to 12 led to the formation of $\mathrm{Ni}(\mathrm{OH})_{2}$ nanoplates with a thickness of 20-50 nm (see Figs. 1(b) and 1(e)). At pH 13, it is interesting to observe that the $\mathrm{Ni}(\mathrm{OH})_{2}$ nanoplates are
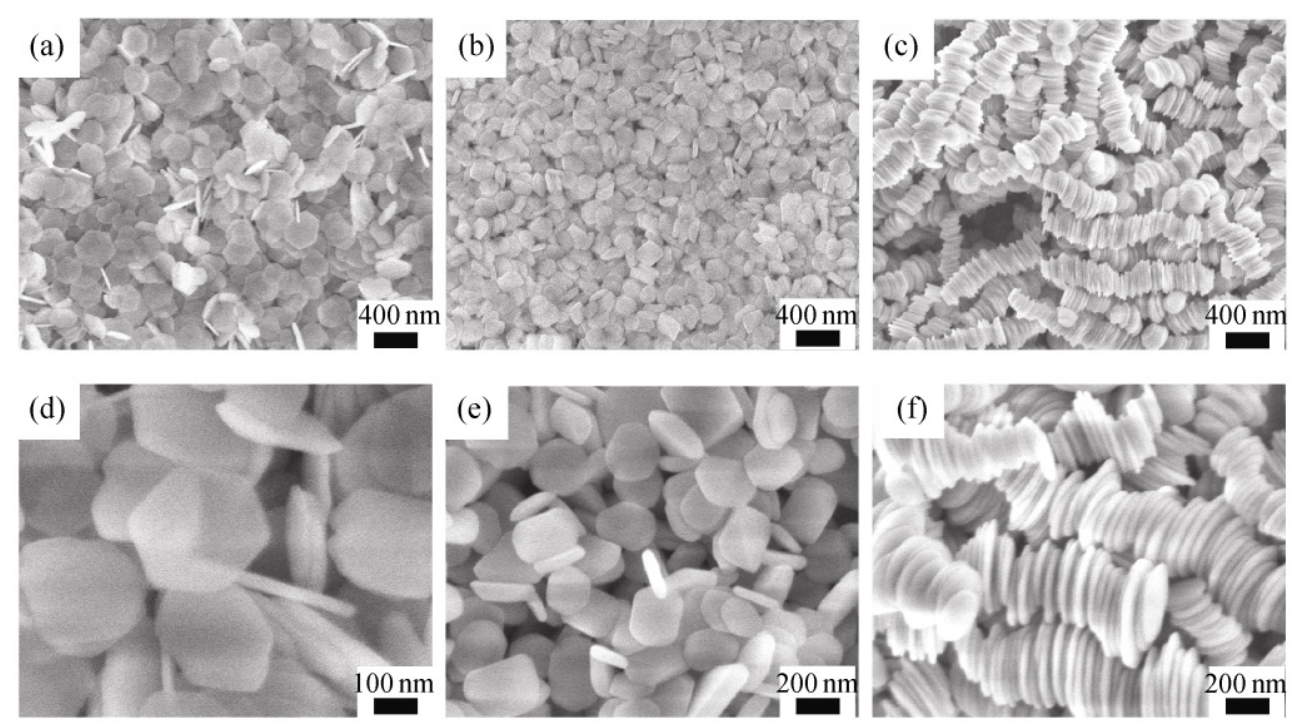

Figure 1 Representative SEM images of as-prepared $\beta-\mathrm{Ni}(\mathrm{OH})_{2}$ nanocrystals. (a, d) Nanoslices with diameters of 200-400 nm and thicknesses of 5-10 nm. (b, e) Nanoplates with diameters of 100-300 nm and thicknesses of 20-50 nm. (c, f) Nanocolumns with diameters of $200-400 \mathrm{~nm}$ and heights of $1-2 \mu \mathrm{m}$ 
stacked via their basal surfaces to form columnar structures with diameters ranging from 200 to $400 \mathrm{~nm}$ and heights of 1-2 $\mu \mathrm{m}$ (see Figs. 1(c) and 1(f)). The HRTEM images (see Figs. S-1(a)-S-1(c) in the Electronic Supplementary Material (ESM)) of as-prepared $\mathrm{Ni}(\mathrm{OH})_{2}$ reveal that the nanoslices and nanoplates are single crystalline. The nanocolumns are formed by stacking the nanoplates along the [001] direction according to the lattice spacing in the cross-section HRTEM (see Fig. S-1(c) in the ESM).

XRD analysis shows that the as-prepared nanostructures are $\beta-\mathrm{Ni}(\mathrm{OH})_{2}$ (see Fig. 2(a)) and no impurity phases are detected. Annealing these $\beta-\mathrm{Ni}(\mathrm{OH})_{2}$ nanocrystals at $673 \mathrm{~K}$ converted them into $\mathrm{NiO}$ (see Fig. 2(b)). The annealing process also induced a re-crystallization process during the transition from $\beta-\mathrm{Ni}(\mathrm{OH})_{2}$ to $\mathrm{NiO}$; this altered the crystal size as indicated by the changes in the widths of the diffraction peaks in the XRD patterns. On converting $\beta-\mathrm{Ni}(\mathrm{OH})_{2}$ to $\mathrm{NiO}$, the average crystal size changed from $69.4 \mathrm{~nm}, 43.7 \mathrm{~nm}$, and $29.5 \mathrm{~nm}$ to $31.8 \mathrm{~nm}, 22.6 \mathrm{~nm}$, and $12.8 \mathrm{~nm}$ for the nanoslices, nanoplates, and nanocolumns, respectively, as estimated from the Scherrer equation [2].

The generation of nanopores in $\mathrm{NiO}$ nanocrystals is directly revealed by SEM and transmission electron microscopy (TEM) observations (see Fig. 3). The pore sizes are closely related to the nanostructure of $\beta-\mathrm{Ni}(\mathrm{OH})_{2}$. The product obtained by annealing the $\beta-\mathrm{Ni}(\mathrm{OH})_{2}$ nanoslices contained large pores with sizes in the range 15-30 nm (see Figs. 3(a) and 3(d)).
In addition to similar large pores with diameters of $15-30 \mathrm{~nm}$, smaller pores can be observed in the products obtained by annealing the nanoplates $(\sim 10 \mathrm{~nm}$, see Figs. 3(b) and 3(e)) and nanocolumns ( 2 nm, see Figs. 3(c) and 3(f)). The formation of smaller pores in the nanocolumns might be related to their unique structure formed by stacking the slices/plates with their basal surfaces overlapping. The reduced surface area hinders the effective run-away of water generated by thermal decomposition, resulting in a slower water-loss/pore-generation; this favors the formation of smaller pores in the nanocolumns as compared to those in the nanoslices and nanoplates. The TEM images show that individual nanoplates becomes polycrystalline (see Fig. 3(e)), which may be a consequence of the re-crystallization indicated by XRD.

Nitrogen adsorption/desorption isotherms for these porous $\mathrm{NiO}$ nanocrystals show type $\mathrm{H} 3$ hysteresis loops (Fig. 4), which are commonly observed for plate-like particles with slit-shaped pores. Although the pore size distribution plots can be obtained based on the desorption branch data, we cannot draw a firm conclusions about the pore size of these $\mathrm{NiO}$ samples due to the fact that other factors may also be reflected in the isotherms, e.g., the inter-particle spacing may also contribute to the pore size distribution. The specific surface areas were determined to be 102.4, 20.2, and $11.4 \mathrm{~m}^{2} / \mathrm{g}$ for the nanocolumns, nanoplates, and nanoslices, respectively. The higher surface area of the $\mathrm{NiO}$ nanocolumns can be assumed to be related

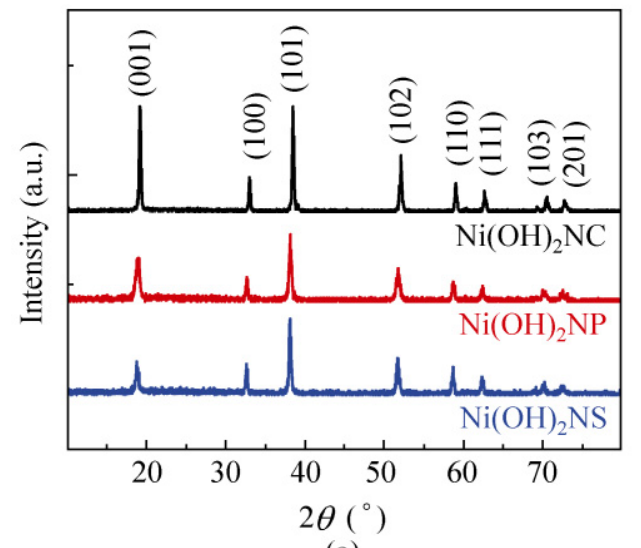

(a)

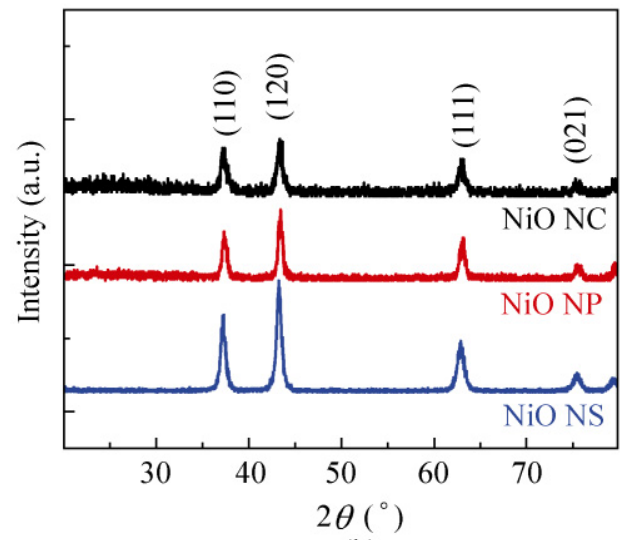

(b)

Figure 2 XRD patterns of (a) $\beta$ - $\mathrm{Ni}(\mathrm{OH})_{2}$ nanocrystals and (b) porous $\mathrm{NiO}$ nanocrystals. NS, NP, and NC denote nanoslices, nanoplates, and nanocolumns, respectively 

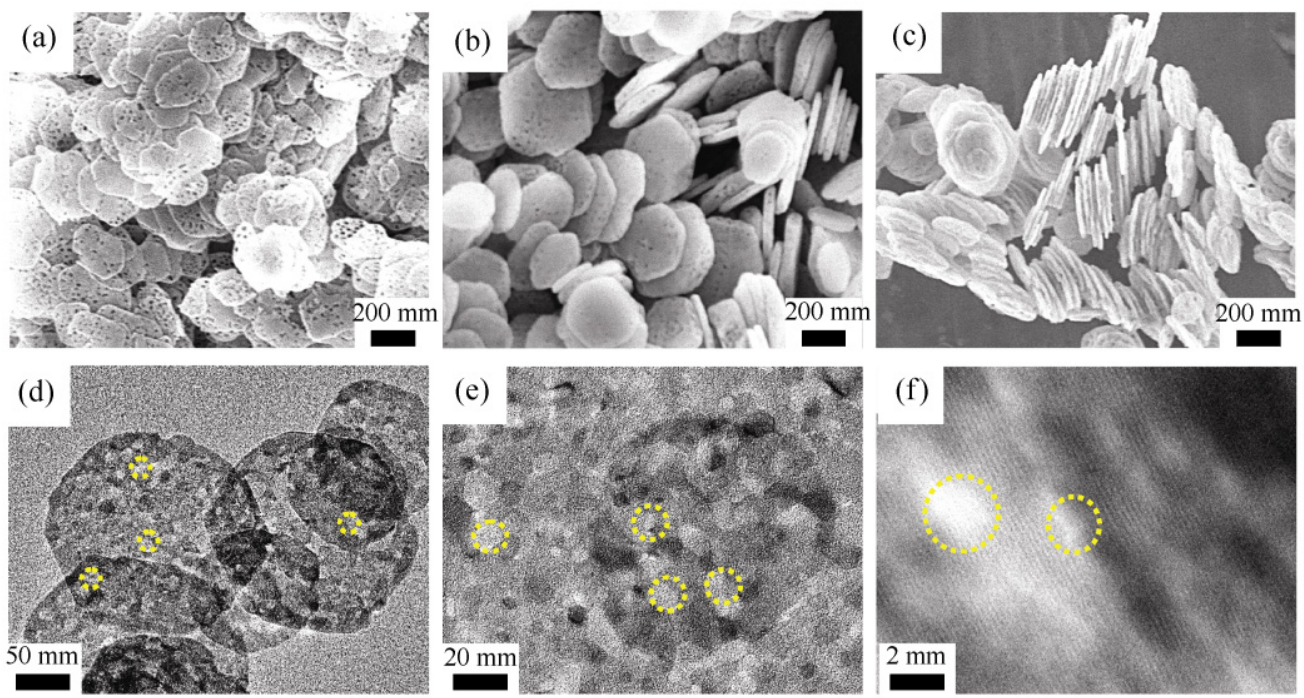

Figure 3 SEM images of the porous NiO nanocrystals: (a) nanoslices, (b) nanoplates, and (c) nanocolumns. HRTEM images of representative porous $\mathrm{NiO}$ nanocrystals: (d) nanoslices with pore sizes of 10-30 nm, (e) nanoplates with pore sizes of 10-25 nm, (f) nanocolumns with pore sizes of $2-5 \mathrm{~nm}$. The dotted yellow circles in (d)-(f) are used to highlight the pores in the NiO nanocrystals

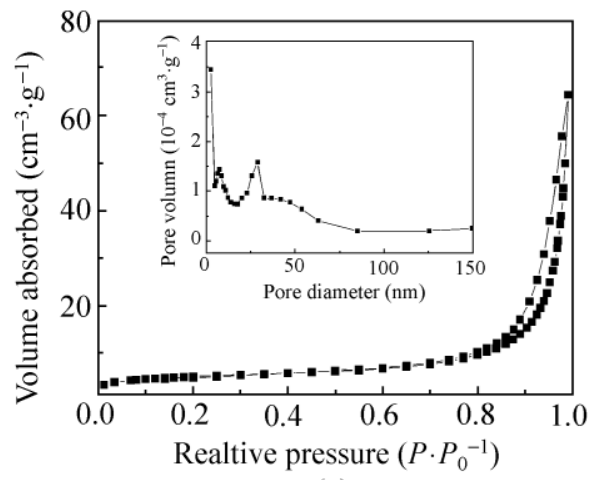

(a)

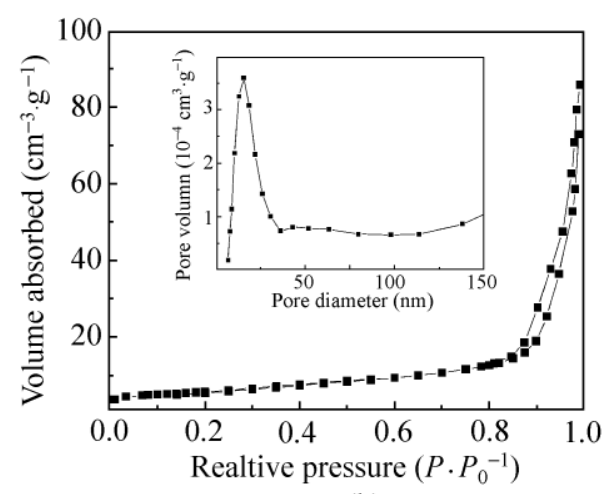

(b)

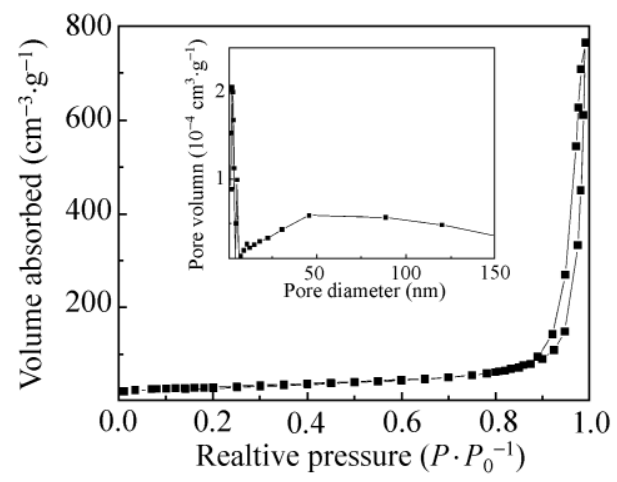

(c)

Figure 4 Nitrogen adsorption and desorption isotherms measured at $77 \mathrm{~K}$ for the (a) porous NiO nanoslices, (b) porous NiO nanoplates, and (c) porous $\mathrm{NiO}$ nanocolumns. The insets show the corresponding BJH pore size distributions 
to the smaller pore diameters. For comparison, the surface areas of the corresponding $\beta-\mathrm{Ni}(\mathrm{OH})_{2}$ precursors are $9.06 \mathrm{~m}^{2} / \mathrm{g}$ for the nanoslices, $7.52 \mathrm{~m}^{2} / \mathrm{g}$ for the nanoplates, and $5.18 \mathrm{~m}^{2} / \mathrm{g}$ for the nanocolumns; these values are all markedly lower than those of the porous $\mathrm{NiO}$ nanostructures (see Figs. S-2(a)-S-2(c) in the ESM).

The thermal decomposition process of $\beta-\mathrm{Ni}(\mathrm{OH})_{2}$ was investigated by thermogravimetric (TG) analysis and differential scanning calorimetry (DSC) (see Fig. 5). The onsets of mass loss in the TG traces occur at 263, 270 , and $282{ }^{\circ} \mathrm{C}$ for the nanoslices, nanoplates, and nanocolumns, respectively, which corresponds to the peak positions in the DSC traces (Fig. 5(b)). The total mass losses are slightly smaller than the theoretical value of $19.4 \%$ [44-46], which indicates incomplete thermal decomposition of the $\beta-\mathrm{Ni}(\mathrm{OH})_{2}$. The values are $19.2 \%$ for the nanoslices (corresponding to $99 \%$ $\mathrm{NiO}$ formation), $18.1 \%$ for nanoplates (corresponding to $94.7 \% \mathrm{NiO}$ formation) and $17.6 \%$ for nanocolumns (corresponding to $93.4 \% \mathrm{NiO}$ formation). The amount of residual $\beta-\mathrm{Ni}(\mathrm{OH})_{2}$ is below the XRD detection limit, however (Fig. 2(b)). Although the total water loss for the nanocolumns was lower than that for the nanoslices and nanoplates, it should be noted that the specific surface area is larger due to the generation of smaller pores.

The electrochemical performances of the porous $\mathrm{NiO}$ nanocrystals were compared by means of $\mathrm{CV}$ and chronopotentiometric measurements in $1 \mathrm{~mol} / \mathrm{L}$ $\mathrm{KOH}$ aqueous solution in the potential range -0.3 to $0.7 \mathrm{~V}$ vs. SCE at a galvanostatic current density of
$5 \mathrm{~A} / \mathrm{g}$. For nickel oxide as an electrode material, it is well accepted that the surface Faradaic reaction can be expressed as follows:

$$
\mathrm{NiO}+\mathrm{OH}^{-} \longleftrightarrow \mathrm{NiOOH}+\mathrm{e}^{-}
$$

A pair of cathodic and anodic peaks is clearly observed in the CV curves for all three samples (see Fig. 6). The specific capacitances $C_{\mathrm{s}}$ were calculated from the galvanostatic discharge curves using the equation [47]:

$$
C_{\mathrm{s}}=\frac{i}{-\frac{\Delta V}{\Delta t} m}=\frac{i}{- \text { slope } \times m}
$$

where $i$ is the current applied, $\Delta V / \Delta t$ is the slope of the discharge curve after the $i R$ drop, and $m$ is the mass of the sample on one electrode. The specific capacitance values calculated from the discharge curves are $390 \mathrm{~F} / \mathrm{g}$ for the porous $\mathrm{NiO}$ nanocolumns, $285 \mathrm{~F} / \mathrm{g}$ for the nanoplates and $176 \mathrm{~F} / \mathrm{g}$ for the nanoslices. The remarkable enhancement in the specific capacitance of the porous $\mathrm{NiO}$ nanocolumns can mainly be attributed to their higher specific surface area and smaller pores, which provide effective diffusion channels for the electrolyte ions leading to an improved pseudocapacitive performance. In particular, such porous nanostructures can act as "ion-buffering reservoirs" [48], which sustain the supply of $\mathrm{OH}^{-}$ions and ensure that sufficient Faradic reactions can take place at high current densities for energy storage. The cyclability of the porous $\mathrm{NiO}$ nanostructures was tested by continuous charge-discharge measurements over 1000 cycles (see Fig. 7) at a current

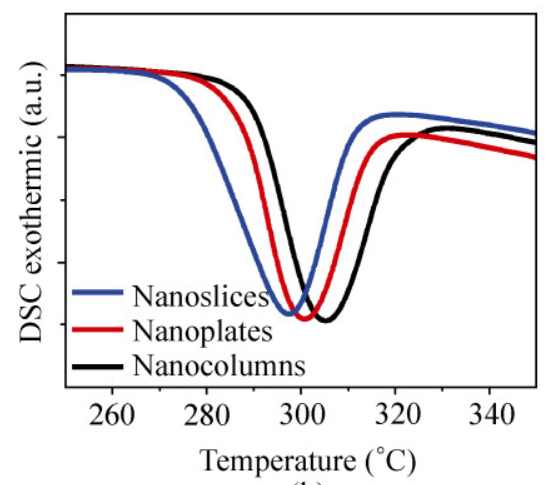

(b)

Figure 5 (a) TGA and (b) DSC curves associated with the conversion process from $\beta$-Ni( $\mathrm{OH})_{2}$ nanocrystals to porous NiO nanostructures. The tests were conducted in air with a heating rate of $10 \mathrm{~K} / \mathrm{min}$ 


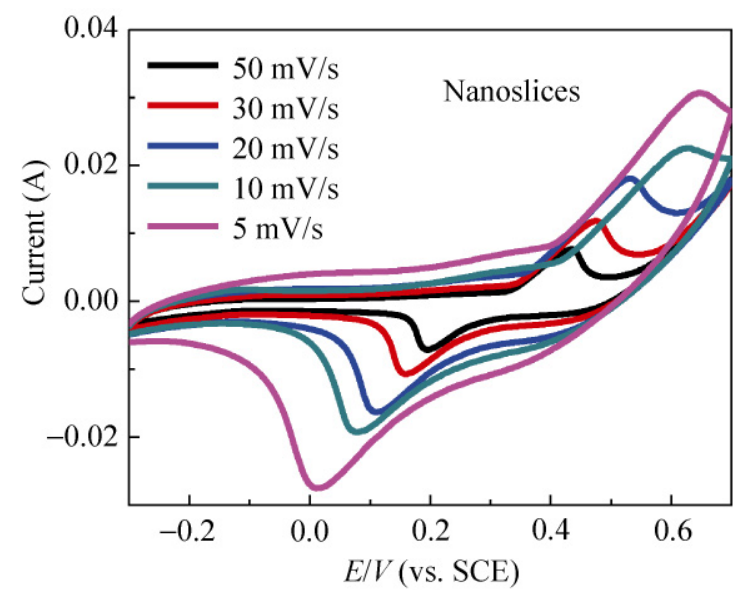

(a)

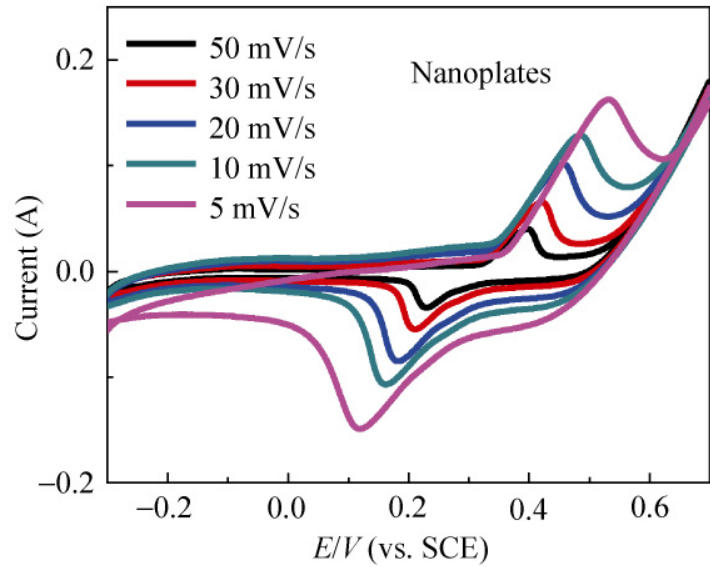

(b)

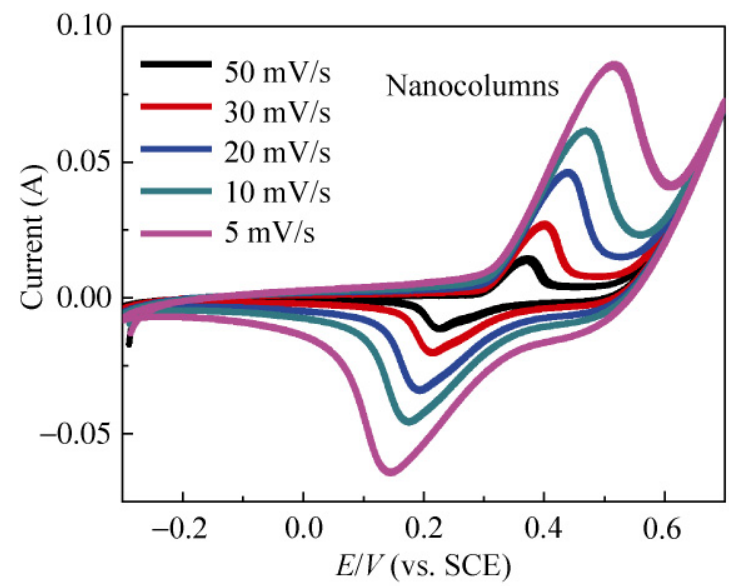

(c)

Figure 6 Cyclic voltammograms of porous $\mathrm{NiO}$ nanocrystals in $1 \mathrm{~mol} / \mathrm{L} \mathrm{KOH}$ aqueous solution with different scan rates: (a) nanoslices, (b) nanoplates, and (c) nanocolumns

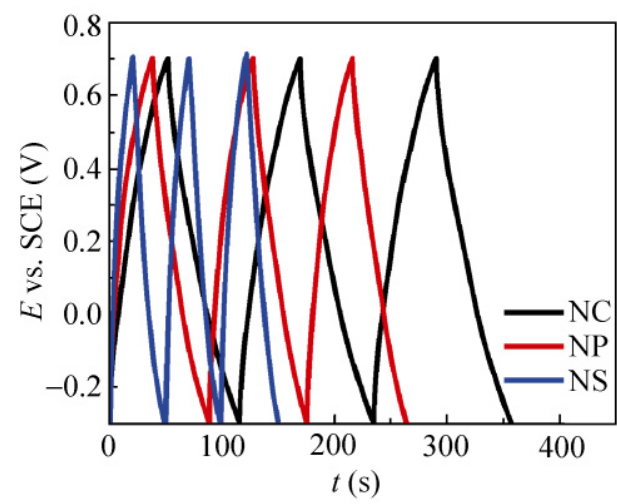

(a)

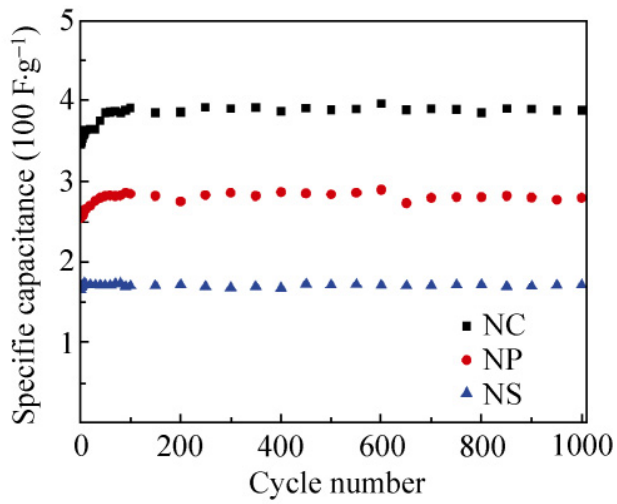

(b)

Figure 7 (a) Galvanostatic charge/discharge curves measured with a current density of $5 \mathrm{~A} / \mathrm{g}$ for porous NiO nanocrystals. (b) Cycling performance for porous $\mathrm{NiO}$ nanocrystals at a current density of $5 \mathrm{~A} / \mathrm{g}$ in $1 \mathrm{~mol} / \mathrm{L}$ aqueous $\mathrm{KOH}$. NS, NP, and NC denote nanoslices, nanoplates, and nanocolumns, respectively 
density of $5 \mathrm{~A} / \mathrm{g}$ and a voltage range of -0.3 to $0.7 \mathrm{~V}$. The specific capacitances increase by about $8 \%-14 \%$ for all three types of $\mathrm{NiO}$ during the first 50 cycles, which is possibly due to the activation process of the $\mathrm{NiO}$ electrodes [26]. After this increase, the specific capacitances of the porous $\mathrm{NiO}$ nanocrystals are maintained as the charge/discharge process continued, which confirms the stable cycling performance as well as the high coulombic efficiency. Since the amounts of residual $\mathrm{Ni}(\mathrm{OH})_{2}$ in the samples are very low $(1 \%-6 \%)$ as indicated by the thermogravimetric analysis (TGA) data, it should not contribute significantly to the measured specific capacitances. The charge-discharge curves and cycling performance of the $\mathrm{NiO}$ nanocolumns at different current densities (1-5 A/g) between -0.30 and $0.70 \mathrm{~V}$ (vs. SCE) are shown in Fig. 8. Increasing the current density from $1 \mathrm{~A} / \mathrm{g}$ to $5 \mathrm{~A} / \mathrm{g}$ results in a reduction in the charge capacity from $686 \mathrm{~F} / \mathrm{g}$ to $390 \mathrm{~F} / \mathrm{g}$ while a stable cycling performance is maintained.

\section{Conclusions}

Porous NiO nanoslices, nanoplates and nanocolumns with different specific surface areas have been prepared by thermal decomposition of $\beta$ - $\mathrm{Ni}(\mathrm{OH})_{2}$ nanostructures In electrochemical tests, these porous $\mathrm{NiO}$ nanostructures show stable cycling performance with the retention of specific capacitance over 1000 cycles. The

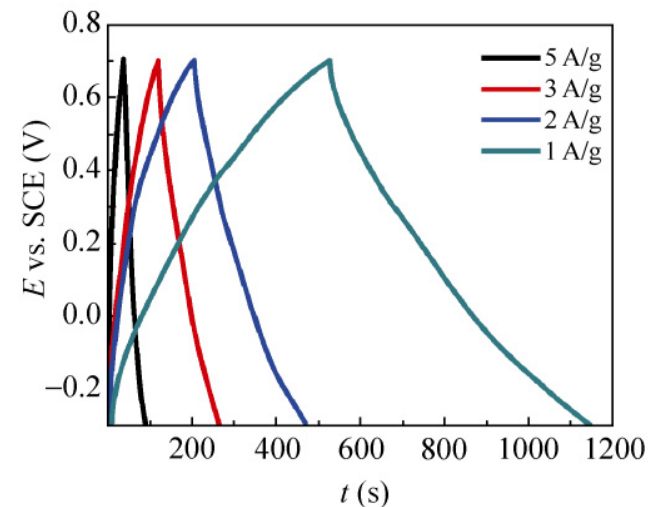

(a) formation of nanocolumns by stacking $\beta-\mathrm{Ni}(\mathrm{OH})_{2}$ nanoslices/plates is the crucial factor in the formation of small pores in the $\mathrm{NiO}$ nanocrystals obtained after annealing the sample, and result in their surface area being much larger than that of $\mathrm{NiO}$ obtained by annealing $\mathrm{Ni}(\mathrm{OH})_{2}$ nanoslices or nanoplates. When tested as electrodes for supercapacitors, the specific capacitance of the porous $\mathrm{NiO}$ nanocolumns is much higher than that of the nanoslices or nanoplates. This approach also offers a potential strategy to enhance the performance of supercapacitors made of a variety of other materials.

\section{Acknowledgements}

The authors gratefully acknowledge the AcRF Tier 1 RG 31/08 from Ministry of Education Singapore and No. NRF2009EWT-CERP001-026 Singapore, the National Natural Science Foundation of China (No. 20901003), the Natural Science Foundation of the Educational Department of Anhui Province (No. KJ2008B167) and the Young Teacher Program of Anhui Normal University (No. 2009xqnzc19).

Electronic Supplementary Material: Supplementary material (HRTEM micrograph of $\mathrm{NiO}$ nanomaterials and BET data for $\mathrm{Ni}(\mathrm{OH})_{2}$ nanomaterials) is available in the online version of this article at http://dx.doi.org/ $10.1007 / \mathrm{s} 12274-010-0024-6$ and is accessible free of charge.

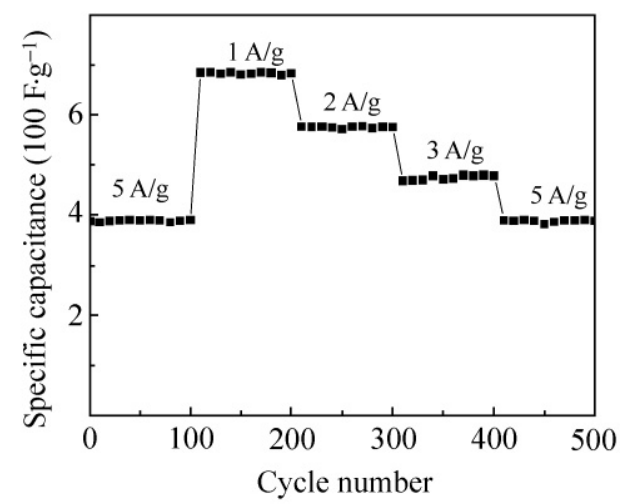

(b)

Figure 8 (a) Galvanostatic charge/discharge curves measured with different current densities for porous NiO nanocolumns. (b) Cycling performance for porous $\mathrm{NiO}$ nanocolumns at different current densities in $1 \mathrm{~mol} / \mathrm{L}$ aqueous $\mathrm{KOH}$ 
Open Access: This article is distributed under the terms of the Creative Commons Attribution Noncommercial License which permits any noncommercial use, distribution, and reproduction in any medium, provided the original author(s) and source are credited.

\section{References}

[1] Kim, E.; Son, D.; Kim, T. G.; Cho, J.; Park, B.; Ryu, K. S.; Chang, S. H. A mesoporous/crystalline composite material containing tin phosphate for use as the anode in lithium-ion batteries. Angew. Chem. Int. Ed. 2004, 43, 5987-5990.

[2] Lou, X. W.; Deng, D.; Lee, J. Y.; Archer, L. A. Thermal formation of mesoporous single-crystal $\mathrm{Co}_{3} \mathrm{O}_{4}$ nano-needles and their lithium storage properties. J. Mater. Chem. 2008, 18, 4397-4401.

[3] Lou, X. W.; Deng, D.; Lee, J. Y.; Feng, J.; Archer, L. A. Self-supported formation of needlelike $\mathrm{Co}_{3} \mathrm{O}_{4}$ nanotubes and their application as lithium-ion battery electrodes. $A d v$. Mater. 2008, 20, 258-262.

[4] Lin, Z. Z.; Jiang, F. L.; Chen, L.; Yue, C. Y.; Yuan, D. Q.; Lan, A. J.; Hong, M. C. A highly symmetric porous framework with multi-intersecting open channels. Cryst. Growth Des. 2007, 7, 1712-1715.

[5] Wan, Y.; Zhao, D. Y. On the controllable soft-templating approach to mesoporous silicates. Chem. Rev. 2007, 107, 2821-2860

[6] Zhao, Q. R.; Zhang, Z. G.; Dong, T.; Xie, Y. Facile synthesis and catalytic property of porous tin dioxide nanostructures. J. Phys. Chem. B 2006, 110, 15152-15156.

[7] Seisenbaeva, G. A.; Moloney, M. P.; Tekoriute, R.; HardyDessources, A.; Nedelec, J. M.; Gun'ko, Y. K.; Kessler, V. G. Biomimetic synthesis of hierarchically porous nanostructured metal oxide microparticles-potential scaffolds for drug delivery and catalysis. Langmuir 2010, 26, 9809-9817.

[8] Wang, Z. L.; Liu, R. X.; Zhao, F. Y.; Liu, X. J.; Lv, M. F.; Meng, J. Facile synthesis of porous $\mathrm{Fe}_{7} \mathrm{Co}_{3} /$ carbon nanocomposites and their applications as magnetically separable adsorber and catalyst support. Langmuir 2010, 26, 10135 10140.

[9] Sadek, A. Z.; Zheng, H. D.; Breedon, M.; Bansal, V.; Bhargava, S. K.; Latham, K.; Zhu, J. M.; Yu, L. S.; Hu, Z.; Spizzirri, P. G.; Wlodarski, W.; Kalantar-Zadeh, K. Hightemperature anodized $\mathrm{WO}_{3}$ nanoplatelet films for photosensitive devices. Langmuir 2009, 25, 9545-9551.

[10] Robinson, D. B.; Wu, C. A. M.; Ong, M. D.; Jacobs, B. W.; Pierson, B. E. Effect of electrolyte and adsorbates on charging rates in mesoporous gold electrodes. Langmuir 2010, 26, 6797-6803.
[11] Stimpfling, T.; Leroux, F. Supercapacitor-type behavior of carbon composite and replica obtained from hybrid layered double hydroxide active container. Chem. Mater. 2010, 22, 974-987.

[12] Carriazo, D.; Pico, F.; Gutierrez, M. C.; Rubio, F.; Rojo, J. M.; Monte, F. Block-copolymer assisted synthesis of hierarchical carbon monoliths suitable as supercapacitor electrodes. $J$. Mater. Chem. 2010, 20, 773-780.

[13] Wang, K. X.; Wang, Y. G.; Wang, Y. R.; Hosono, E.; Zhou, H. S. Mesoporous carbon nanofibers for supercapacitor application. J. Phys. Chem. C 2009, 113, 1093-1097.

[14] Suppes, G. M.; Deore, B. A.; Freund, M. S. Porous conducting polymer/heteropolyoxometalate hybrid material for electrochemical supercapacitor applications. Langmuir 2008, 24, 1064-1069.

[15] Davis, M. E. Ordered porous materials for emerging applications. Nature 2002, 417, 813-821.

[16] Sun, Y. K.; Kim, D. H.; Yoon, C. S.; Myung, S. T.; Prakash, J.; Amine, K. A novel cathode material with a concentration-gradient for high-energy and safe lithium-ion batteries. Adv. Funct. Mater. 2010, 20, 485-491.

[17] Nam, K. W.; Leea, C. W.; Yang, X. Q.; Choc, B. W.; Yoon, W. S.; Kim, K. B. Electrodeposited manganese oxides on three-dimensional carbon nanotube substrate: Supercapacitive behaviour in aqueous and organic electrolytes. J. Power Sources 2009, 188, 323-331.

[18] Li, C.; Wei, W.; Fang, S. M.; Wang, H. X.; Zhang, Y.; Gui, Y. H.; Chen, R. F. A novel CuO-nanotube $/ \mathrm{SnO}_{2}$ composite as the anode material for lithium ion batteries. J. Power Sources 2010, 195, 2939-2944.

[19] Fu, G. R.; Hu, Z. A.; Xie, L. J.; Jin, X. Q.; Xie, Y. L.; Wang, Y. X.; Zhang, Z. Y.; Yang, Y. Y.; Wu, H. Y. Electrodeposition of nickel hydroxide films on nickel foil and its electrochemical performances for supercapacitor. Int. J. Electrochem. Sci. 2009, 4, 1052-1062.

[20] Yang, G. W.; Xu, C. L.; Li, H. L. Electrodeposited nickel hydroxide on nickel foam with ultrahigh capacitance. Chem. Commun. 2008, 6537-6539.

[21] Wang, H. L.; Casalongue, H. S.; Liang, Y. Y.; Dai, H. J. $\mathrm{Ni}(\mathrm{OH})_{2}$ nanoplates grown on graphene as advanced electrochemical pseudocapacitor materials. J. Am. Chem. Soc. 2010, 132, 7472-7477.

[22] Liu, K. C.; Anderson, M. A. Porous nickel oxide/nickel films for electrochemical capacitors. J. Electrochem. Soc. 1996, 143, 124-130.

[23] Nam, K. W.; Kim, K. B. A study of the preparation of $\mathrm{NiO}_{x}$ electrode via electrochemical route for supercapacitor applications and their charge storage mechanism. $J$. Electrochem. Soc. 2002, 149, 346-354. 
[24] Chang, K. H.; Hu, C. C.; Chou, C. Y. Textural and capacitive characteristics of hydrothermally derived $\mathrm{RuO}_{2} \cdot x \mathrm{H}_{2} \mathrm{O}$ nanocrystallites: Independent control of crystal size and water content. Chem. Mater. 2007, 19, 2112-2119.

[25] Hu, C. C.; Chang, K. H.; Lin, M. C.; Wu Y. T. Design and tailoring of the nanotubular arrayed architecture of hydrous $\mathrm{RuO}_{2}$ for next generation supercapacitors Nano Lett. 2006, 6, 2690-2695.

[26] Yuan, C. Z.; Zhang, X. G.; Su, L. H.; Gao, B.; Shen, L. F. Facile synthesis and self-assembly of hierarchical porous $\mathrm{NiO}$ nano/micro spherical superstructures for high performance supercapacitors. J. Mater. Chem. 2009, 19, 5772-5777.

[27] Lang, J. W.; Kong, L. B.; Wu, W. J.; Luo, Y. C.; Kang, L. Facile approach to prepare loose-packed $\mathrm{NiO}$ nano-flakes materials for supercapacitors. Chem. Commun. 2008, 4213 4215.

[28] Zhu, J. X.; Gui, Z. From layered hydroxide compounds to labyrinth-like $\mathrm{NiO}$ and $\mathrm{Co}_{3} \mathrm{O}_{4}$ porous nanosheets. Mater. Chem. Phys. 2009, 118, 243-248.

[29] Qiu, Y. J.; Yu, J.; Zhou, X. S.; Tan, C. L.; Yin, J. Synthesis of porous $\mathrm{NiO}$ and $\mathrm{ZnO}$ submicro- and nanofibers from electrospun polymer fiber templates. Nanoscale Res. Lett. 2009, 4, 173-177.

[30] Yuan, C. Z.; Chen, L.; Gao, B.; Su, L. H.; Zhang, X. G. Synthesis and utilization of $\mathrm{RuO}_{2} \cdot x \mathrm{H}_{2} \mathrm{O}$ nanodots well dispersed on poly(sodium 4-styrene sulfonate) functionalized multi-walled carbon nanotubes for supercapacitors. J. Mater Chem. 2009, 19, 246-252.

[31] Yuan, C. Z.; Gao, B.; Zhang, X. G. Electrochemical capacitance of $\mathrm{NiO} / \mathrm{Ru}_{0.35} \mathrm{~V}_{0.65} \mathrm{O}_{2}$ asymmetric electrochemical capacitor. J. Power Sources 2007, 173, 606-612.

[32] Xing, W.; Li, F.; Yan, Z. F.; Lu, G. Q. Synthesis and electrochemical properties of mesoporous nickel oxide. $J$. Power Sources 2004, 134, 324-330.

[33] Jiao, F.; Hill, A. H.; Harrison, A.; Berko, A.; Chadwick, A. V.; Bruce, P. G. Synthesis of ordered mesoporous $\mathrm{NiO}$ with crystalline walls and a bimodal pore size distribution. J. Am. Chem. Soc. 2008, 130, 5262-5266.

[34] Yan, H. W.; Blanford, C. F.; Holland, B. T.; Parent, M.; Smyrl, W. H.; Stein, A. A chemical synthesis of periodic macroporous $\mathrm{NiO}$ and metallic Ni. Adv. Mater. 1999, 11, 1003-1006.

[35] Wei, T. Y.; Chen, C. H.; Chien, H. C.; Lu, S. Y.; Hu, C. C. A cost-effective supercapacitor material of ultrahigh specific capacitances: Spinel nickel cobaltite aerogels from an epoxidedriven sol-gel process. Adv. Mater. 2010, 22, 347-351.

[36] Brezesinski, K.; Wang, J.; Haetge, J.; Reitz, C.; Steinmueller, S. O.; Tolbert, S. H.; Smarsly, B. M.; Dunn, B.; Brezesinski, T. Pseudocapacitive contributions to charge storage in highly ordered mesoporous group $\mathrm{V}$ transition metal oxides with iso-oriented layered nanocrystalline domains. $\mathrm{J} \mathrm{Am}$. Chem. Soc. 2010, 132, 6982-6990.

[37] Han, Y.; Zhang, D. L.; Chang, L. L.; Sun, J. L.; Zhao, L.; Zou, X. D.; Ying, J. Y. A tri-continuous mesoporous material with a silica pore wall following a hexagonal minimal surface. Nature Chem. 2009, 1, 123-127.

[38] Chen, C.; Cai, W. M.; Long, M. C.; Zhang, J. Y.; Zhou, B. X.; Wu, Y. H.; Wu, D. Y. Template-free sol-gel preparation and characterization of free-standing visible light responsive $C, N$-modified porous monolithic $\mathrm{TiO}_{2}$. J Hazard. Mater. 2010, 178, 560-565.

[39] Hu, X. L.; Li, G. S.; Yu, J. C. Design, fabrication, and modification of nanostructured semiconductor materials for environmental and energy applications. Langmuir 2010, 26, 3031-3039.

[40] Frey, S.; Keipert, S.; Chazalviel, J. N.; Ozanam, F.; Carstensen, J.; Foll, H. Electrochemical formation of porous silica: Toward an understanding of the mechanisms. Phys. Status Solidi A 2007, 204, 1250-1254.

[41] Kresge, C. T.; Leonowicz, M. E.; Roth, W. J.; Vartuli, J. C.; Beck, J. S. Ordered mesoporous molecular sieves synthesized by a liquid-crystal template mechanism. Nature 1992, 359, 710-712.

[42] Zhang, Z. Y.; Zuo, F.; Feng, P. Y. Hard template synthesis of crystalline mesoporous anatase $\mathrm{TiO}_{2}$ for photocatalytic hydrogen evolution. J. Mater. Chem. 2010, 20, 2206-2212.

[43] Peterson, A. K.; Morgan, D. G.; Skrabalak, S. E. Aerosol synthesis of porous particles using simple salts as a pore template. Langmuir 2010, 26, 8804-8809.

[44] Justin, P.; Meher, S. K.; Rao, G. R. Tuning of capacitance behavior of $\mathrm{NiO}$ using anionic, cationic, and nonionic surfactants by hydrothermal synthesis. J. Phys. Chem. C 2010, 114, 5203-5210.

[45] Zhao, B.; Ke, X. K.; Bao, J. H.; Wang, C. L.; Dong, L.; Chen, Y. W.; Chen, H. L. Synthesis of flower-like NiO and effects of morphology on its catalytic properties. J. Phys. Chem. C 2009, 113, 14440-14447.

[46] Kuang, D. B.; Lei, B. X.; Pan, Y. P.; Yu, X. Y.; Su, C. Y. Fabrication of novel hierarchical $\beta-\mathrm{Ni}(\mathrm{OH})_{2}$ and $\mathrm{NiO}$ microspheres via an easy hydrothermal process. J. Phys. Chem. C 2009, 113, 5508-5513.

[47] Kaempgen, M.; Chan, C. K.; Ma, J.; Cui, Y.; Grune, G. Printable thin film supercapacitors using single-walled carbon nanotubes. Nano Lett. 2009, 9, 1872-1876.

[48] Wang, D. W.; Li, F.; Liu, M.; Lu, G. Q.; Cheng, H. M. 3D aperiodic hierarchical porous graphitic carbon material for high-rate electrochemical capacitive energy storage. Angew. Chem., Int. Ed. 2007, 48, 373-376. 